(1)

CrossMark

\title{
Interaction between asthma and smoking increases the risk of adult airway obstruction
}

\author{
Marianne Aanerud ${ }^{1}$, Anne-Elie Carsin ${ }^{2,3}$, Jordi Sunyer ${ }^{2-4}$, Julia Dratva ${ }^{5}$, \\ Thorarinn Gislason ${ }^{6}$, Deborah Jarvis ${ }^{7}$, Roberto deMarco ${ }^{8}$, Chantal Raherison ${ }^{9}$, \\ Matthias Wjst ${ }^{10}$, Shyamali C. Dharmage ${ }^{11}$ and Cecilie Svanes ${ }^{12,13}$
}

\begin{abstract}
Affiliations: 'Dept of Medicine, Haukeland University Hospital, Bergen, Norway. ${ }^{2}$ Centre for Research in Environmental Epidemiology (CREAL), Barcelona, Spain. ${ }^{3} \mathrm{Hospital}$ del Mar Research Institute (IMIM), Barcelona, Spain. ${ }^{4}$ Universitat Pompeu Fabra, Barcelona, Spain. ${ }^{5}$ Institute of Social and Preventive Medicine at the Swiss Tropical Institute, Basel, Switzerland. ${ }^{6}$ Dept of Respiratory Medicine and Sleep, Landspitali University Hospital (E7) and Faculty of Medicine, University of Iceland, Reykjavik, Iceland. ${ }^{7}$ Dept of Public Health Sciences, Imperial College, London, UK. ${ }^{8}$ Dept of Medicine and Public Health/Epidemiology and Medical Statistics, University of Verona, Verona, Italy. ${ }^{9}$ INSERM, ISPED, Centre INSEM U897, CHU Bordeaux, Bordeaux, France. ${ }^{10} \mathrm{Helmholtz}$ Center Munich, National Research Centre for Environmental Health, Comprehensive Pneumology Center, Institute of Lung Biology and Disease, Munich, Germany. ${ }^{11}$ Centre for Molecular, Environmental, Genetic and Analytic Epidemiology, School of Population Health, The University of Melbourne, Melbourne, Australia. ${ }^{12}$ Dept of Occupational Medicine, Haukeland University Hospital, Bergen, Norway. ${ }^{13}$ Centre for International Health, University of Bergen, Bergen, Norway.
\end{abstract}

Correspondence: Marianne Aanerud, Dept of Medicine, Haukeland University Hospital, Jonas Lies vei 1, 5021 Bergen, Norway. E-mail: marianne.aanerudamed.uib.no

ABSTRACT The aim of the present study was to analyse the interaction between asthma and smoking in the risk of adult airway obstruction, accounting for atopy.

In the European Community Respiratory Health Survey, 15668 persons aged 20-56 years underwent spirometry in 1991-1993 and 9 years later $(n=8916)$. Risk of airway obstruction and lung function decline associated with smoking and early-onset ( $<10$ years of age) and late-onset ( $>10$ years of age) asthma were analysed with generalised estimating equation models and random-effect linear models, adjusting for covariates. Interaction of asthma with smoking was expressed as relative excess risk due to interaction (RERI).

A 20-fold increase in adult airway obstruction was found among those with early-onset asthma independently of smoking status (never-smokers: OR 21.0, 95\% CI 12.7-35; current smokers: OR 23.7, 95\% CI 13.9-40.6). Late-onset asthma was associated with airway obstruction, with a stronger association among current smokers (OR 25.6, 95\% CI 15.6-41.9) than among never-smokers (OR 11.2, 95\% CI 6.818.6) (RERI 12.02, 95\% CI 1.96-22.07). Stratifying by atopy, the association between smoking and asthma was most pronounced among nonatopics.

Early- and late-onset asthma were associated with 10-20-fold increased risk of adult airway obstruction. Smoking increased the risk of adult airway obstruction in subjects with asthma onset after age 10 years. Investigation of measures potentially preventive of chronic obstructive pulmonary disease development following asthma is urgently needed.

@ERSpublications

Early-onset asthma increased adult airflow obstruction risk 20-fold; smoking modified effects of late-onset asthma http://ow.ly/CMNqU

For editorial comments see Eur Respir J 2015; 45: 586-588 [DOI: 10.1183/09031936.00231414].

This article has supplementary material available from erj.ersjournals.com

Received: March 242014 | Accepted after revision: Oct 042014 | First published online: Nov 272014

Conflict of interest: None declared.

Copyright OERS 2015 


\section{Introduction}

There is some evidence that asthma is an important risk factor for adult airway obstruction and chronic obstructive pulmonary disease (COPD). Longitudinal studies have indicated that subjects with asthma have lower baseline forced expiratory volume in $1 \mathrm{~s}(\mathrm{FEV} 1)$ and faster FEV1 decline than subjects without asthma [1-7], and that subjects with asthma are more likely to fulfil the criteria for COPD [5]. Asthma is the most common chronic condition in childhood, but it can occur at any age, and the risk of COPD related to having had asthma seems to vary according to age of asthma onset [8]. Smoking is the main cause of COPD in affluent parts of the world. For example, in a Swedish study, the population-attributable fraction of ever-smoking in COPD ranged from $29 \%$ to $64 \%$, depending on sex and definition of COPD [9]. However, smoking alone does not explain the variance in lung function and lung function decline over time. One might question whether early-onset asthma might influence the susceptibility to the harmful effects of smoking.

In addition to asthma, atopy may play a role in the relationship between asthma and adult airway obstruction. Subjects with asthma and atopy are more likely to enter adulthood with lower maximum attained lung function compared with subjects with asthma alone [10]. Moreover, atopy has been associated with accelerated FEV1 decline, both in subjects with and without asthma $[11,12]$.

Understanding the relationship between smoking, asthma with different ages at onset, atopy and airway obstruction might provide prognostic information in asthma, but it can also identify target groups for COPD prevention. Most current knowledge about risk factors for COPD relates to the elderly, while very little is known about airway obstruction in the younger adult cohorts toward whom future preventive strategies should be aimed. With the recent asthma epidemic in the Western world and the substantial worldwide burden of COPD [13-16], identifying vulnerable groups among younger cohorts is an important task that may impact global health. The present study aimed to meet this need. Data from the European Community Respiratory Health Survey (ECRHS) cohort of younger adults were used to estimate the risk of airway obstruction associated with asthma by age of asthma onset, to evaluate whether interaction between smoking and asthma by age of onset increased the risk of airway obstruction, and to evaluate whether atopy modifies the relationships between asthma, smoking and airway obstruction.

\section{Methods}

\section{Study population}

The ECRHS I (1991-1993) randomly selected adults aged 20-44 years from the general population in 25 countries to answer a short screening questionnaire regarding lung health [17]. A random sample of those answering, in addition to a subsample of individuals who reported asthma symptoms in the screening questionnaire, were invited to participate in the main study, which comprised face-to-face interviews, spirometry and blood tests. A total of 15668 subjects (13 361 from the randomly selected and 2307 from the symptomatic samples in 29 centres, representing $85 \%$ of those eligible) completed a questionnaire, underwent spirometry and gave blood samples. After a mean follow up time of 8.9 years (interquartile range 8.3-9.5 years), altogether, 8916 persons (7738 subjects from the random sample and 1448 from the symptomatic sample), then aged 26-56 years, repeated spirometry [18]. The study was performed with the approval of the local regional committees of medical research ethics. The full protocol is available at www.ecrhs.org

\section{Lung function and definition of airway obstruction}

The maximum FEV1 and maximum forced vital capacity (FVC) from up to five technically acceptable manoeuvres were measured applying the American Thoracic Society criteria for reproducibility. Airway obstruction was defined as pre-bronchodilator $\mathrm{FEV}_{1} / \mathrm{FVC}<0.70$ and $\mathrm{FEV}_{1}<80 \%$ predicted. We performed additional analyses using the FEV1/FVC below the lower limit of normal (LLN) according to age and sex, with LLN equations obtained from 2536 "normal" nonsmokers attending the ECRHS I. Difference between the two FEV1 measurements in millilitres per year defined lung function decline. The centre in Melbourne, Australia, had changed spirometer in ECRHS II and they recorded lung function increase in the ECHRS II, so the ECRHS II data from Melbourne were excluded [6]. Subjects who participated only in ECRHS I contributed lung function measurements once, while subjects participating in the follow-up survey contributed twice, hence forming the longitudinal information on lung function.

\section{Definition of asthma and covariates}

Information on asthma and smoking were obtained by interviewer-administered questionnaires. The answer to the question "Have you ever had asthma?" defined asthma. Age of asthma onset was defined as early ( $<10$ years) or late ( $>10$ years) asthma. Smoking was categorised as never-, former or current, where current smokers reported smoking during the last month in the ECRHS II. The number of pack-years (20 cigarettes per day for 1 year) defined smoking intensity. Body mass index (BMI) was calculated from height and weight measured before spirometry. Age on completing education was used as a proxy variable for educational level. Specific IgE levels were measured with the Pharmacia CAP System (GE Healthcare, 
Uppsala, Sweden) [19] and atopy was defined as an assay result $>0.35 \mathrm{kU} \cdot \mathrm{L}^{-1}$ for any of the following allergens: house dust mite (Dermatophagoides pteronyssimus), timothy grass (Phleum pratense), cat dander (Felis domesticus) and moulds (Cladosporium herbarum).

\section{Statistical analyses}

The associations between asthma and airway obstruction were analysed using generalised estimating equation modelling (a semiparametric regression technique) adjusting for potential confounders (age, sex, country, education, BMI, height, smoking and sample (i.e. random or symptomatic)) while taking into account that spirometry measurements were repeated at two different time-points. The fractions of airway obstruction attributable to asthma and smoking were calculated using the Rockhill method [20]. Interactions between asthma and smoking in relation to risk of airway obstruction were investigated by estimating the relative excess risks due to interaction (RERIs) and their confidence intervals [21]. Mixed-effect linear regression was used to examine associations between lung function decline and asthma. Centre was included as a random effect in all models. Models were adjusted for age (mean age during follow-up and age squared), height (standardised by sex), difference in BMI, BMI (mean BMI during follow-up), sex, education, FEV1 \% predicted at baseline and sample. Interactions between asthma and smoking on lung function decline were evaluated overall and by atopy status. The statistical analyses were conducted using Stata version 10.1 (StatCorp, College Station, TX, USA).

\section{Results}

A total of 15668 individuals with at least one lung function measurement were included, yielding 24584 observations. A comparison of baseline characteristics among those with and without airway obstruction at baseline is provided in table 1 . In subjects with late-onset asthma, median age of asthma onset was 24 years and mean age of asthma onset was 26 years. Altogether, there were 509 observations of airway obstruction in ECRHS I and II. Airway obstruction was rare (0.4\%) in never-smoking subjects without asthma, and most prevalent among former and current smoking subjects with asthma ( $>12 \%)$ (table 2). Subjects with early- and late-onset asthma had lower baseline lung function than subjects without asthma. Currently smoking subjects had the largest annual lung function decline; among never-smokers, the decline was largest among those with early-onset asthma.

Adjusted analyses showed that current smokers had a 4.5 times higher risk of airway obstruction, compared with never-smokers, among subjects without asthma (table 3). The risk of airway obstruction when having early-onset asthma was increased $>20$-fold, regardless of smoking status (table 3 ). The association did not vary significantly between centres in meta-analyses (data not shown). There was no detectable relative excess risk of airway obstruction due to interaction between current smoking and early-onset asthma. Current smokers with late-onset asthma had a higher risk of airway obstruction compared with never-smoking subjects with late-onset asthma (table 3), and there was a significant RERI between current smoking and late-onset asthma of 12.02 (95\% CI 1.96-22.07). Exclusion of subjects with airway obstruction at baseline rendered similar results (online supplementary table E1). The interaction between late-onset asthma and current smoking was present both when smoking was initiated before and after asthma onset (tables E2 and E3). Lung function decline was higher among those with asthma as well as among current smokers compared with never-smokers without asthma (table 3 ).

Analysing the risk of airway obstruction according to age of asthma onset in 5-year age groups stratified by sex (fig. 1 and table E4) showed that risk of airway obstruction was greatly increased in those with early-onset asthma in both men and women, and that current smoking had limited additional impact in these groups. In those with asthma onset between 10 and 14 years, current smoking increased the risk of airway obstruction in both sexes (males: OR 12.5 (95\% CI 6.6-13.9) and 26.7 (95\% CI 14.0-29.6) for nonsmokers and current smokers, respectively; females: OR 11.0 (95\% CI 6.9-18.2) and 51.7 (95\% CI 30.6-74.8) for nonsmokers and current smokers, respectively) (table E4).

The percentage of airway obstruction attributable to asthma (35.3\%) was approximately as high as the percentage of airway obstruction attributable to smoking (former and current smoking combined, 36.0\%) (table E5).

Stratified by atopy, smoking and early- and late-onset asthma were independent risk factors for adult airflow obstruction. Current smokers with late-onset asthma had an increased risk of adult airway obstruction compared with never-smokers with late-onset asthma, regardless of atopic status. There was a significant relative excess risk of airway obstruction in current smoking subjects with late-onset asthma only in those without atopy (RERI 18,95\% CI 0.3-35.6), meaning that the effect of current smoking and late-onset asthma in those without atopy is larger than the effect of the two risk factors added together. The effect of smoking in early-onset asthma was different according to atopic status, with similar odds ratios for adult airway obstruction in both never- and current smokers with early-onset asthma and atopy (table 4). 
TABLE 1 Cohort characteristics at baseline by adult airway obstruction ${ }^{\#}$

\begin{tabular}{|c|c|c|c|}
\hline & \multicolumn{2}{|c|}{ Adult airway obstruction } & \multirow[t]{2}{*}{ Total } \\
\hline & No & Yes & \\
\hline Total & $15243(100.0)$ & $425(100.0)$ & $15668(100.0)$ \\
\hline \multicolumn{4}{|l|}{ Age } \\
\hline$<30$ years & 5320 (34.9) & 93 (21.9) & $5413(34.6)$ \\
\hline 30-38 years & 5041 (33.1) & $138(32.5)$ & 5179 (33.1) \\
\hline$\geqslant 38$ years & $4879(32.0)$ & $194(45.6)$ & $5073(32.4)$ \\
\hline Age years & $33.7(27.6-39.9)$ & $37.2(30.9-42.1)$ & $33.8(27.6-40.0)$ \\
\hline Age at follow-up years & $43.1(37.0-49.0)$ & $46.3(40.6-51.2)$ & $43.2(37.1-49.1)$ \\
\hline \multicolumn{4}{|l|}{ Sex } \\
\hline Males & $7413(48.6)$ & $247(58.1)$ & 7660 (48.9) \\
\hline Females & $7830(51.4)$ & $178(41.9)$ & 8008 (51.1) \\
\hline \multicolumn{4}{|l|}{ Asthma } \\
\hline No & $13301(87.6)$ & $192(45.7)$ & $13493(86.4)$ \\
\hline Early onset ${ }^{\natural}$ & $796(5.2)$ & $110(26.2)$ & $906(5.8)$ \\
\hline Late onset $^{+}$ & $1092(7.2)$ & $118(28.1)$ & $1210(7.8)$ \\
\hline \multicolumn{4}{|l|}{ Smoking } \\
\hline Never & $6454(43.0)$ & $127(30.7)$ & $6581(42.7)$ \\
\hline Former & $3114(20.7)$ & $73(17.6)$ & $3187(20.7)$ \\
\hline \multicolumn{4}{|l|}{ Current } \\
\hline 0-10 pack-years & 2382 (15.9) & $49(11.8)$ & 2431 (15.8) \\
\hline $10-20$ pack-years & $1634(10.9)$ & $57(13.8)$ & $1691(11.0)$ \\
\hline$>20$ pack-years & $1426(9.5)$ & $108(26.1)$ & $1534(9.9)$ \\
\hline Atopy $\$$ & 4532 (33.8) & $206(54.6)$ & 4738 (34.3) \\
\hline \multicolumn{4}{|l|}{ Age on completing education } \\
\hline$>22$ years & $3741(26.3)$ & 86 (22.5) & $3827(26.2)$ \\
\hline $18-22$ years & $4366(30.7)$ & $83(21.7)$ & 4449 (30.5) \\
\hline$\leqslant 18$ years & $6105(43.0)$ & $214(55.9)$ & $6319(43.3)$ \\
\hline \multicolumn{4}{|l|}{ Childhood factors } \\
\hline Maternal asthma & $1013(6.9)$ & 49 (12.2) & $1062(7.0)$ \\
\hline Paternal asthma & $896(6.3)$ & $72(18.4)$ & $968(6.6)$ \\
\hline Paternal atopy & 2086 (15.2) & $76(20.2)$ & 2162 (15.3) \\
\hline Maternal atopy & 3049 (21.5) & $76(19.8)$ & $3125(21.5)$ \\
\hline Infection $<5$ years of age & $1554(10.9)$ & $82(21.4)$ & $1636(11.1)$ \\
\hline Maternal smoking & $3822(25.4)$ & $129(31.4)$ & $3951(25.6)$ \\
\hline \multicolumn{4}{|l|}{ Country } \\
\hline Australia & $715(4.7)$ & 42 (9.9) & $757(4.8)$ \\
\hline Belgium & $787(5.2)$ & $22(5.2)$ & 809 (5.2) \\
\hline Estonia & $476(3.1)$ & $9(2.1)$ & $485(3.1)$ \\
\hline France & $2076(13.6)$ & $40(9.4)$ & $2116(13.5)$ \\
\hline Germany & $1673(11.0)$ & $28(6.6)$ & $1701(10.9)$ \\
\hline Iceland & $592(3.9)$ & $17(4.0)$ & 609 (3.9) \\
\hline Italy & $897(5.9)$ & $13(3.1)$ & $910(5.8)$ \\
\hline The Netherlands & $387(2.5)$ & $4(0.9)$ & $391(2.5)$ \\
\hline Norway & $751(4.9)$ & $22(5.2)$ & 773 (4.9) \\
\hline Spain & 2105 (13.8) & $69(16.2)$ & 2174 (13.9) \\
\hline Sweden & 2057 (13.5) & $37(8.7)$ & $2094(13.4)$ \\
\hline Switzerland & $907(6.0)$ & $38(8.9)$ & $945(6.0)$ \\
\hline UK & $1380(9.1)$ & $76(17.9)$ & $1456(9.3)$ \\
\hline USA & $440(2.9)$ & $8(1.9)$ & $448(2.9)$ \\
\hline \multicolumn{4}{|l|}{ Participation in ECRHS } \\
\hline Only ECRHS I & 7044 (46.2) & $171(40.2)$ & 7215 (46.0) \\
\hline Both ECRHS I and II & 8199 (53.8) & 254 (59.8) & 8453 (54.0) \\
\hline
\end{tabular}

Data are presented as $\mathrm{n}(\%)$ or median (interquartile range). ECRHS: European Community Respiratory Health Survey. " : pre-bronchodilator forced expiratory volume in $1 \mathrm{~s}(\mathrm{FEV} 1) /$ forced vital capacity ratio $<70 \%$ and $\mathrm{FEV} 1<80 \%$ predicted measured either at the ECRHS I or $\|_{;}{ }^{\natural}:<10$ years of age; ${ }^{+}$: $>10$ years of age; $\S$ : assay result $>0.35 \mathrm{kU} \cdot \mathrm{L}^{-1}$ for house dust mite, timothy grass, cat dander or moulds. 
TABLE 2 Adult airway obstruction", forced expiratory volume in $1 \mathrm{~s}$ (FEV1) at baseline and FEV1 change by smoking status and asthma

\begin{tabular}{lcccc} 
& Total & Never-smokers & Former smokers & Current smokers \\
\hline $\begin{array}{l}\text { Adult airway obstruction } \mathbf{n}(\%) \\
\quad \text { No asthma }\end{array}$ & $209(1.0)$ & $33(0.4)$ & $42(0.9)$ & $134(1.8)$ \\
$\quad$ Early-onset asthma & $138(10.1)$ & $59(8.8)$ & $36(12.2)$ & $43(10.7)$ \\
$\quad$ Late-onset asthma & $162(8.3)$ & $57(6.2)$ & $35(7.6)$ & $70(12.3)$ \\
$\quad$ Total & $509(2.1)$ & $149(1.5)$ & $113(2.1)$ & $247(3.0)$ \\
Baseline FEV 1 L & & & & \\
$\quad$ No asthma & $3.77 \pm 0.8$ & $3.78 \pm 0.9$ & $3.80 \pm 0.8$ & $3.75 \pm 0.8$ \\
$\quad$ Early-onset asthma & $3.61 \pm 0.9$ & $3.63 \pm 0.9$ & $3.52 \pm 0.8$ & $3.62 \pm 0.8$ \\
$\quad$ Late-onset asthma & $3.34 \pm 0.8$ & $3.38 \pm 0.9$ & $3.38 \pm 0.8$ & $3.24 \pm 0.8$ \\
$\quad$ Total & $3.73 \pm 0.8$ & $3.73 \pm 0.9$ & $3.71 \pm 0.8$ & $3.75 \pm 0.8$ \\
FEV change & & & & \\
$\quad$ No asthma & & & & \\
$\quad$ Early-onset asthma & $-28.72 \pm 32.42$ & $-27.05 \pm 31.47$ & $-28.62 \pm 30.44$ & $-31.04 \pm 35.13$ \\
$\quad$ Late-onset asthma & $-29.49 \pm 44.39$ & $-30.97 \pm 44.06$ & $-24.85 \pm 42.57$ & $-31.92 \pm 47.25$ \\
$\quad$ Total & $-28.55 \pm 41.96$ & $-28.52 \pm 40.69$ & $-27.05 \pm 40.95$ & $-30.18 \pm 45.42$ \\
& $-28.75 \pm 34.17$ & $-27.46 \pm 33.50$ & $-28.27 \pm 32.30$ & $-31.01 \pm 36.60$ \\
\hline
\end{tabular}

Data are presented as mean \pm SD unless otherwise stated. * : pre-bronchodilator $\mathrm{FEV}_{1} /$ forced vital capacity ratio $<70 \%$ and $\mathrm{FEV} 1<80 \%$ predicted measured either at the European Community Respiratory Health Survey (ECRHS) I or II; measurements from both surveys are used, thus one individual may contribute with two measurements. ": FEV1 in the ECRHS II minus FEV1 in ECRHS I.

Among subjects without atopy, never-smoking subjects with asthma (both early- and late-onset) had mean FEV1 declines similar to those of never-smoking subjects without asthma. Among those with atopy, FEV1 decline was greater in subjects with asthma (both early- and late-onset), independently of current smoking (table 4).

All analyses were repeated using the LLN definition of airway obstruction and the results were essentially similar (data not shown).

\section{Discussion}

The risk of airway obstruction was increased 20-fold among people with early-onset asthma, regardless of smoking status. These findings appeared to be homogenous between 36 study centres in the Western world, with varying traditions for diagnosing asthma and varying smoking habits. The risk of airway

TABLE 3 Adjusted associations of asthma and smoking status with adult airway obstruction\# and forced expiratory volume in $1 \mathrm{~s}(\mathrm{FEV} 1)$ change

\begin{tabular}{cc}
\multicolumn{2}{c}{ Adult airway obstruction } \\
\hline Subjects $\% \quad$ OR $^{\text {I }}(95 \% \mathrm{CI})$
\end{tabular}

\begin{tabular}{cc}
\multicolumn{2}{c}{ FEV1 change per year } \\
\hline Mean change $^{+}$ & Adjusted difference \\
$\mathrm{mL}^{+}$year $^{-1}$ & $\mathrm{~mL}(95 \% \mathrm{Cl})$
\end{tabular}

\begin{tabular}{|c|c|c|c|c|}
\hline \multicolumn{5}{|l|}{ No asthma } \\
\hline Never-smokers & 0.3 & 1.00 & -25.79 & 0 \\
\hline Current smokers & 1.5 & $4.54(2.95-6.99)$ & -32.15 & $-6.35(-8.21--4.50)$ \\
\hline \multicolumn{5}{|l|}{ Early-onset asthma } \\
\hline Never-smokers & 6.9 & $21.01(12.67-34.94)$ & -33.47 & $-7.68(-12.18--3.17)$ \\
\hline Current smokers & 7.8 & 23.72 (13.86-40.58) & -38.57 & $-12.78(-19.14--6.43)$ \\
\hline \multicolumn{5}{|l|}{ Late-onset asthma } \\
\hline Never-smokers & 3.7 & 11.21 (6.75-18.60) & -29.59 & $-3.80(-7.49--0.11)$ \\
\hline Current smokers & 8.4 & $25.60(15.64-41.90)$ & -33.96 & $-8.17(-13.07--3.27)$ \\
\hline
\end{tabular}

\#: pre-bronchodilator $\mathrm{FEV}_{1} /$ forced vital capacity ratio $<70 \%$ and $\mathrm{FEV}_{1}<80 \%$ predicted measured either at the European Community Respiratory Health Survey (ECRHS) I or II; ": from generalised estimation equation models, adjusted for sample, age, sex, height, country and education; ${ }^{+}$: from mixed-effect linear regression, adjusted for $\mathrm{FEV} 1$ at baseline, education, age, height, body mass index (BMI) change, BMI, sample, sex and country. 

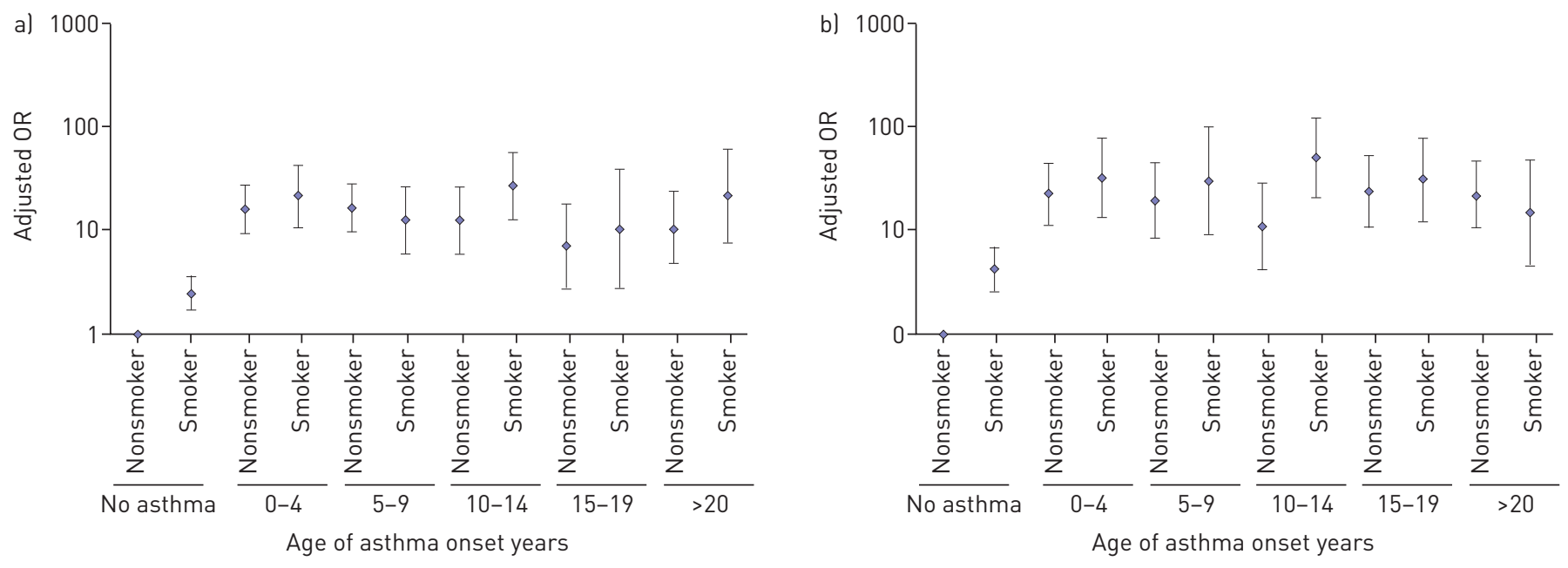

FIGURE 1 Association between asthma and airway obstruction in a) men and b) women, by age of asthma onset and smoking status. Estimates from generalised estimation equation modelling adjusted for age, height, study sample, country and education.

obstruction in subjects with late-onset asthma was significantly increased in current smokers compared with never-smokers, an effect that was prominent only for adolescent-onset asthma. The risk of adult airway obstruction in subjects with atopy and early-onset asthma was not related to smoking status. Smoking increased the risk of adult airway obstruction in subjects with late-onset asthma, regardless of atopic status. The population-attributable fractions for asthma and current smoking in relation to airway obstruction were similar (36\% versus 35\%), a finding supported by similar magnitude of effects of asthma

TABLE 4 Association of asthma and smoking status in relation to adult airway obstruction" stratified by atopy

\begin{tabular}{|c|c|c|c|}
\hline \multicolumn{2}{|c|}{ Adult airway obstruction } & \multicolumn{2}{|c|}{ FEV1 change } \\
\hline COPD \% & $O R^{\pi}(95 \% \mathrm{CI})$ & $\begin{array}{c}\text { Mean }^{+} \\
\text {mL-year }\end{array}$ & $\begin{array}{c}\text { Coefficient }{ }^{+} \\
(95 \% \mathrm{CI})\end{array}$ \\
\hline
\end{tabular}

\begin{tabular}{|c|c|c|c|c|}
\hline \multicolumn{5}{|l|}{ No atopy } \\
\hline \multicolumn{5}{|l|}{ No asthma } \\
\hline Never-smokers & 0.4 & 1.00 & -26.1 & 0 \\
\hline Current smokers & 1.7 & $4.56(2.69-7.74)$ & -32.8 & $-6.65(-8.82--4.48)$ \\
\hline \multicolumn{5}{|l|}{ Early-onset asthma } \\
\hline Never-smokers & 3.1 & $6.93(2.02-23.76)$ & -25.7 & $0.46(-8.17-9.09)$ \\
\hline Current smokers & 9.1 & $22.22(9.71-50.84)$ & -34.2 & $-8.09(-17.90-1.71)$ \\
\hline \multicolumn{5}{|l|}{ Late-onset asthma } \\
\hline Never-smokers & 5.6 & $9.73(4.47-21.14)$ & -26.2 & $-0.01(-6.03-6.01)$ \\
\hline Current smokers & 14.9 & $30.33(15.48-59.41)$ & -38.4 & $-12.25(-19.42--5.08)$ \\
\hline \multicolumn{5}{|l|}{ Atopy } \\
\hline \multicolumn{5}{|l|}{ No asthma } \\
\hline Never-smokers & 0.5 & 1.00 & -23.9 & 0 \\
\hline Current smokers & 1.7 & $3.25(1.55-6.80)$ & -28.2 & $-4.31(-8.38--0.24)$ \\
\hline \multicolumn{5}{|l|}{ Early-onset asthma } \\
\hline Never-smokers & 11.3 & $19.41(9.42-40.00)$ & -37.4 & $-13.53(-19.81--7.26)$ \\
\hline Current smokers & 11.0 & $18.41(8.38-40.47)$ & -38.5 & $-14.60(-24.09--5.12)$ \\
\hline \multicolumn{5}{|l|}{ Late-onset asthma } \\
\hline Never-smokers & 7.1 & $9.43(4.48-19.84)$ & -31.6 & $-7.71(-13.20--2.22)$ \\
\hline Current smokers & 11.8 & $17.59(8.26-37.47)$ & -30.4 & $-6.48(-14.04-1.08)$ \\
\hline
\end{tabular}

COPD: chronic obstructive pulmonary disease; FEV1: forced expiratory volume in $1 \mathrm{~s}$. ${ }^{\#}$ : pre-bronchodilator $\mathrm{FEV}_{1} /$ forced vital capacity ratio $<70 \%$ and $\mathrm{FEV}_{1}<80 \%$ predicted measured either at the European Community Respiratory Health Survey (ECRHS) I or II; ": from generalised estimation equation models adjusted for sample, age, height, country, education and sex; ${ }^{+}$: from mixed-effects linear regression adjusted for FEV1 at baseline, education, age, height, body mass index (BMI) change, BMI, sample, sex and country. 
and current smoking on lung function decline $(7.7 \mathrm{~mL}$ larger decline among nonasthmatic current smokers versus $6.4 \mathrm{~mL}$ larger decline among never-smokers with early-onset asthma). These findings regarding airway obstruction in a cohort of relatively young adults are of particular interest when trying to understand COPD in future generations, a necessity when planning prevention strategies.

One of the weaknesses in the study is that the asthma diagnosis can be afflicted by recall bias, as asthma and time of onset were assessed retrospectively. Subjects with current respiratory symptoms might be more likely to remember having had similar problems in the past, while those who outgrew their asthma might not report having had it. This will lead to overestimation of the effect of early-onset asthma on adult airway obstruction. Furthermore, age of asthma onset can be uncertain when questioned several years later. Error in recall of age of asthma onset is likely to be nondifferential with regard to measured airflow obstruction years and decades later; thus, such recall bias would tend to attenuate associations rather than produce spurious associations.

Our finding of a strong association between asthma and airway obstruction is supported by other studies $[2,8,22-24]$. Both lower maximum achieved lung function and accelerated FEV1 decline can explain the increased risk of adult airway obstruction carried by subjects with asthma. GUERRA et al. [8] found that the development of persistent airflow limitation in adulthood in subjects with asthma before 25 years of age were mainly associated with deficits already established earlier in life. In our study, baseline lung function was lower among subjects with early- and with late-onset asthma compared with subjects without asthma. Both in childhood and adulthood, low lung function appears to precede asthma development [25, 26]. This suggests that impaired lung development among asthmatics contribute to explaining their increased risk of adult airway obstruction. Furthermore, we found faster FEV1 decline in subjects with early-onset asthma, which can further contribute to their elevated risk of adult airway obstruction [27]. Studies that surveyed younger subjects $[23,28]$ with a smaller age range [29] have not found significantly accelerated FEV1 decline in subjects with early-onset asthma. We also observed significantly increased FEV1 decline among subjects with late-onset asthma compared with subjects without asthma. However, the differences in yearly FEV1 decline between subjects with and without asthma were relatively modest compared with the magnitude of the association between airway obstruction and asthma. This emphasises the importance of impaired lung development and growth as a risk factor for adult airway obstruction.

Subjects with atopy tend to attain lower maximum lung function [30] and have greater FEV1 decline [12]. There are conflicting reports as to whether the association between atopy and lung function is accounted for by asthma [30,31] or not [32]. Stratified by asthma and smoking, we found that atopy was associated with significantly increased risk of airway obstruction both in subjects with and without asthma (table E6). These results suggest that atopy alone, as well as in the absence of manifest asthma, might reflect low-grade inflammatory processes that can lead to airway obstruction. PERRET et al. [22] found that that atopy increased the risk of adult airflow obstruction, when taking smoking and asthma lifetime history into account. However, when adjusting for lung function at age 7 years, atopy was no longer an independent risk factor for adult airway obstruction. PerRet et al. [22] found a three-way interaction between asthma, smoking and atopic sensitivity, which we could not reproduce in our data. The methodology of the study by Perret et al. [22] is different to that of our study, both in terms of asthma definition and definition of atopy (PERRET et al. [22] used skin-prick testing whereas we used serum measurements of specific IgE).

We found no interaction between early-onset asthma and current smoking. However, in those with asthma onset during adolescence, current smoking greatly increased the risk of airway obstruction. The age group where current smoking interacted with asthma onset to increase risk of airway obstruction coincided with an age when lung growth is maximal. Thus, subjects with asthma onset during adolescence and during the age of the most rapid lung growth might be particularly vulnerable to smoking. Furthermore, the mechanisms predisposing subjects to asthma could also influence the vulnerability to smoking. One may speculate whether such vulnerability could also be present for other airborne pollutants.

Addressing former smokers, we found that in subjects with early-onset asthma, the risk of airway obstruction for former smokers was similar to that in never- and current smokers (table E3). However, in subjects without asthma or with late-onset asthma, the risk of airway obstruction for former smokers was similar to the risk in never-smokers. Similar risk of airway obstruction among never- and former smokers suggest that a healthy smoker effect is unlikely in our data. However, there were $41 \%$ never-smokers among subjects without asthma, whereas $49 \%$ of subjects with early-onset asthma were never-smokers, which indicated a selection into smoking by asthma status. In addition, the mean number of pack-years smoked was lower for current smokers with early-onset asthma than with no asthma (mean 6.6 versus 7.8, respectively). Subjects without asthma had more extreme values for pack-years of smoking than those without asthma (fig. E1). Excluding subjects with extreme numbers of pack-years (>100) from the interaction analyses did not alter our inferences. 
We use the term "airway obstruction" instead of COPD in the present study because we only had pre-bronchodilator measurements. Reversibility testing was not possible because measurements of bronchial hyperactivity were performed. Using pre-bronchodilator values (as opposed to post-bronchodilator spirometry), some subjects with reversible bronchial obstruction will be defined as having airway obstruction [33]. Conversely, this prevents excluding some subjects with airway obstruction who respond to bronchodilator with a relatively larger increase in FVC than in FEV1. Furthermore, post-bronchodilator measurements do not secure exclusion of all subjects with asthma, as several subjects with asthma have nonreversible airflow limitation $[34,35]$. The similar findings for airway obstruction and FEV1 decline in this study suggest that airway obstruction in pre-bronchodilator spirometry measurements could be used as a proxy for COPD. The strict definition of COPD used in both clinical and epidemiological studies (and in treatment guidelines) has been criticised [36]. The post-bronchodilator COPD disease definition may capture the majority of, but far from all, subjects with COPD, as asthma and COPD may coexist or overlap, known as the asthma and COPD overlap syndrome [35-40]. The present study suggests that asthma might evolve into COPD by increasing susceptibility to smoking. Whether the natural history of chronic airflow obstruction evolving from asthma is similar to the natural history of COPD caused by smoking is not known. Some advocate viewing asthma and COPD as different expressions of a single disease entity (the Dutch hypothesis) [41, 42]. From this perspective, subjects with concomitant asthma and persistent airflow obstruction add valuable information to the body of knowledge of COPD. More studies, both epidemiological and clinical, should be conducted including subjects with all phenotypes of asthma and COPD.

There were 67 individuals with airway obstruction in ECRHS I, but not at follow-up. As participants were not surveyed if suffering from acute respiratory infections, acute asthma exacerbations are not likely to be the cause of airflow obstruction. The percentage of subjects having asthma in ECRHS I was not significantly different among those with remission of airflow obstruction compared to those with persistent airflow limitation in ECRHS I and II) (62.7\% and 60.8\%, respectively) (table E7). Sensitivity analyses conducted without the subjects with remittent airflow limitation did not alter the results (table E1).

We investigated interactions on the additive scale in order to identify subgroups of the population that may benefit the most from intervention programmes [43]. Inference of multiplicative interaction requires very large risk estimates for the joint factors, and as a result of this, the additive joint effect of risk might be ignored [43]. Therefore, we chose to assess additive interactions because both the condition (persistent airflow obstruction) and exposure (smoking and asthma) are highly prevalent, and we consider information about these interactions to be high relevance for public health.

In conclusion, early-onset asthma was found to be an extremely strong predictor of adult airway obstruction, as was late-onset asthma, in this cohort of relatively young adults. This may partly be due to poor lung development and growth, and partly to larger lung function decline among asthmatics. Public health authorities should prepare for an increase in adult airway obstruction following the asthma epidemic in the Western world. Asthma with onset after age 10 years and current smoking synergised to increase the risk of adult airflow obstruction. This suggests that subjects with asthma, both children and adults, are important target groups for COPD prevention, in which tobacco control plays a key role. Whether asthma treatment may contribute to prevent chronic airway obstruction and COPD urges clarification.

\section{References}

Fletcher C, Peto R. The natural history of chronic airflow obstruction. Br Med J 1977; 1: 1645-1648.

2 James AL, Palmer LJ, Kicic E, et al. Decline in lung function in the Busselton Health Study: the effects of asthma and cigarette smoking. Am J Respir Crit Care Med 2005; 171: 109-114.

3 Lange P, Parner J, Vestbo J, et al. 15-year follow-up study of ventilatory function in adults with asthma. $N$ Engl J Med 1998; 339: 1194-1200.

4 Peat JK, Woolcock AJ, Cullen K. Rate of decline of lung function in subjects with asthma. Eur J Respir Dis 1987; 70: 171-179.

5 Silva GE, Sherrill DL, Guerra S, et al. Asthma as a risk factor for COPD in a longitudinal study. Chest 2004; 126 : $59-65$.

6 Svanes C, Sunyer J, Plana E, et al. Early life origins of chronic obstructive pulmonary disease. Thorax 2010; 65: $14-20$.

7 Ulrik CS, Lange P. Decline of lung function in adults with bronchial asthma. Am J Respir Crit Care Med 1994; 150: 629-634.

8 Guerra S, Sherrill DL, Kurzius-Spencer M, et al. The course of persistent airflow limitation in subjects with and without asthma. Respir Med 2008; 102: 1473-1482.

9 Lindberg A, Bjerg A, Ronmark E, et al. Prevalence and underdiagnosis of COPD by disease severity and the attributable fraction of smoking Report from the Obstructive Lung Disease in Northern Sweden Studies. Respir Med 2006; 100: 264-272.

10 Burrows B, Knudson RJ, Cline MG, et al. A reexamination of risk factors for ventilatory impairment. Am Rev Respir Dis 1988; 138: 829-836. 
11 Weiss ST. Atopy and airways responsiveness in chronic obstructive pulmonary disease. N Engl J Med 1987; 317: $1345-1347$.

12 Weiss ST. Atopy as a risk factor for chronic obstructive pulmonary disease: epidemiological evidence. Am J Respir Crit Care Med 2000; 162: S134-S136.

13 Buist AS, McBurnie MA, Vollmer WM, et al. International variation in the prevalence of COPD (the BOLD Study): a population-based prevalence study. Lancet 2007; 370: 741-750.

14 Buist AS, Vollmer WM, McBurnie MA. Worldwide burden of COPD in high- and low-income countries. Part I. The burden of obstructive lung disease (BOLD) initiative. Int J Tuberc Lung Dis 2008; 12: 703-708.

15 Ko FW, Hui DS, Lai CK. Worldwide burden of COPD in high- and low-income countries. Part III. Asia-Pacific studies. Int J Tuberc Lung Dis 2008; 12: 713-717.

16 Menezes AM, Perez-Padilla R, Hallal PC, et al. Worldwide burden of COPD in high- and low-income countries. Part II. Burden of chronic obstructive lung disease in Latin America: the PLATINO study. Int J Tuberc Lung Dis 2008; 12: 709-712.

17 Burney PG, Luczynska C, Chinn S, et al. The European Community Respiratory Health Survey. Eur Respir J 1994; 7: 954-960.

18 European Community Respiratory Health Survey II Steering Committee. The European Community Respiratory Health Survey II. Eur Respir J 2002; 20: 1071-1079.

19 Jarvis D, Luczynska C, Chinn S, et al. Change in prevalence of IgE sensitization and mean total IgE with age and cohort. J Allergy Clin Immunol. 2005; 116: 675-682.

20 Rockhill B, Newman B, Weinberg C. Use and misuse of population attributable fractions. Am J Public Health 1998; 88: 15-19.

21 Hosmer DW, Lemeshow S. Confidence interval estimation of interaction. Epidemiology 1992; 3: 452-456.

22 Perret JL, Dharmage SC, Matheson MC, et al. The interplay between the effects of lifetime asthma, smoking, and atopy on fixed airflow obstruction in middle age. Am J Respir Crit Care Med 2013; 187: 42-48.

23 Sears MR, Greene JM, Willan AR, et al. A longitudinal, population-based, cohort study of childhood asthma followed to adulthood. N Engl J Med 2003; 349: 1414-1422.

24 Shirtcliffe P, Marsh S, Travers J, et al. Childhood asthma and GOLD-defined chronic obstructive pulmonary disease. Intern Med J 2012; 42: 83-88.

25 Anto JM, Sunyer J, Basagana X, et al. Risk factors of new-onset asthma in adults: a population-based international cohort study. Allergy 2010; 65: 1021-1030.

26 Haland G, Carlsen KC, Sandvik L, et al. Reduced lung function at birth and the risk of asthma at 10 years of age. N Engl J Med 2006; 355: 1682-1689.

27 Edwards CA, Osman LM, Godden DJ, et al. Wheezy bronchitis in childhood: a distinct clinical entity with lifelong significance?. Chest 2003; 124: 18-24.

28 Phelan PD, Robertson CF, Olinsky A. The Melbourne Asthma Study: 1964-1999. J Allergy Clin Immunol 2002; 109: 189-194.

29 Marossy AE, Strachan DP, Rudnicka AR, et al. Childhood chest illness and the rate of decline of adult lung function between ages 35 and 45 years. Am J Respir Crit Care Med 2007; 175: 355-359.

30 Burrows B, Martinez FD. Bronchial responsiveness, atopy, smoking, and chronic obstructive pulmonary disease. Am Rev Respir Dis 1989; 140: 1515-1517.

31 de Meer $\mathrm{G}$, Kerkhof $\mathrm{M}$, Kromhout $\mathrm{H}$, et al. Interaction of atopy and smoking on respiratory effects of occupational dust exposure: a general population-based study. Environ Health 2004; 3: 6.

32 Sunyer J, Soriano J, Anto JM, et al. Sensitization to individual allergens as risk factors for lower FEV1 in young adults. European Community Respiratory Health Survey. Int J Epidemiol 2000; 29: 125-130.

33 Johannessen A, Omenaas ER, Bakke PS, et al. Implications of reversibility testing on prevalence and risk factors for chronic obstructive pulmonary disease: a community study. Thorax 2005; 60: 842-847.

34 The ENFUMOSA cross-sectional European multicentre study of the clinical phenotype of chronic severe asthma. European Network for Understanding Mechanisms of Severe Asthma. Eur Respir J 2003; 22: 470-477.

35 Mannino DM. COPD: epidemiology, prevalence, morbidity and mortality, and disease heterogeneity. Chest 2002; 121: 121S-126S.

36 Gibson PG, Simpson JL. The overlap syndrome of asthma and COPD: what are its features and how important is it?. Thorax 2009; 64: 728-735.

37 Cassino C, Berger KI, Goldring RM, et al. Duration of asthma and physiologic outcomes in elderly nonsmokers. Am J Respir Crit Care Med 2000; 162: 1423-1428.

38 de Marco R, Pesce G, Marcon A, et al. The coexistence of asthma and chronic obstructive pulmonary disease (COPD): prevalence and risk factors in young, middle-aged and elderly people from the general population. PLoS One 2013; 8: e62985.

39 Gibson PG, McDonald VM, Marks GB. Asthma in older adults. Lancet 2010; 376: 803-813.

40 Soriano JB, Davis KJ, Coleman B, et al. The proportional Venn diagram of obstructive lung disease: two approximations from the United States and the United Kingdom. Chest 2003; 124: 474-481.

41 Postma DS, Boezen HM. Rationale for the Dutch hypothesis. Allergy and airway hyperresponsiveness as genetic factors and their interaction with environment in the development of asthma and COPD. Chest 2004; 126: 96S-104S.

42 Sluiter HJ, Koeter GH, de Monchy JG, et al. The Dutch hypothesis (chronic non-specific lung disease) revisited. Eur Respir J 1991; 4: 479-489.

43 Greenland S. Interactions in epidemiology: relevance, identification, and estimation. Epidemiology 2009; 20: 14-17. 